Review Article

\title{
Clinical Symptoms and Types of Samples Are Critical Factors for the Molecular Diagnosis of Symptomatic COVID-19 Patients: A Systematic Literature Review
}

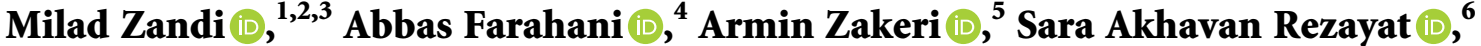 \\ Ramin Mohammadi $\left(\mathbb{D},{ }^{7}\right.$ Umashankar Das $\left(\mathbb{D},{ }^{7}\right.$ Jonathan R. Dimmock $\left(\mathbb{D},{ }^{7}\right.$ Shervin Afzali $\left(\mathbb{D},{ }^{8}\right.$ \\ Mohammadvala Ashtar Nakhaei $\mathbb{D}^{8},{ }^{8}$ Alireza Doroudi $\left(\mathbb{D},{ }^{7}\right.$ Yousef Erfani ${ }^{(D)},{ }^{9}$ \\ and Saber Soltani $(\mathbb{D})^{1,2,3}$ \\ ${ }^{1}$ Department of Virology, School of Public Health, Tehran University of Medical Sciences, Tehran, Iran \\ ${ }^{2}$ Students' Scientific Research Center, Tehran University of Medical Sciences, Tehran, Iran \\ ${ }^{3}$ Research Center for Clinical Virology, Tehran University of Medical Sciences, Tehran, Iran \\ ${ }^{4}$ Infectious and Tropical Diseases Research Center, Hormozgan Health Institute, Hormozgan University of Medical Sciences, \\ Bandar Abbas, Iran \\ ${ }^{5}$ Department of Hematology, Faculty of Medical Sciences, Tarbiat Modares University, Tehran, Iran \\ ${ }^{6}$ Department of Health Economics and Management, School of Public Health, Tehran University of Medical Sciences, \\ Tehran, Iran \\ ${ }^{7}$ Drug Discovery and Development Research Group, College of Pharmacy and Nutrition, University of Saskatchewan, \\ Saskatoon, Canada \\ ${ }^{8}$ Department of Cellular and Molecular Biology, Faculty of Life Sciences and Biotechnology, Shahid Beheshti University G.C., \\ Tehran, Iran \\ ${ }^{9}$ Department of Medical Laboratory Sciences, School of Allied Medical Sciences, Tehran University Medical Sciences, Tehran, Iran
}

Correspondence should be addressed to Saber Soltani; sabersoltani71@gmail.com

Received 22 May 2021; Revised 18 August 2021; Accepted 25 August 2021; Published 11 September 2021

Academic Editor: Todd R. Callaway

Copyright (c) 2021 Milad Zandi et al. This is an open access article distributed under the Creative Commons Attribution License, which permits unrestricted use, distribution, and reproduction in any medium, provided the original work is properly cited.

Background. Currently, a novel coronavirus found in 2019 known as SARS-CoV-2 is the etiological agent of the COVID-19 pandemic. Various parameters including clinical manifestations and molecular evaluation can affect the accuracy of diagnosis. This review aims to discuss the various clinical symptoms and molecular evaluation results in COVID-19 patients, to point out the importance of onset symptoms, type, and timing of the sampling, besides the methods that are used for detection of SARS-CoV-2. Methods. A systematic literature review of current articles in the Web of Science, PubMed, Scopus, and EMBASE was conducted according to the PRISMA guideline. Results. Of the 12946 patients evaluated in this investigation, 7643 were confirmed to be COVID-19 positive by molecular techniques, particularly the RT-PCR/qPCR combined technique (qRT-PCR). In most of the studies, all of the enrolled cases had $100 \%$ positive results for molecular evaluation. Among the COVID-19 patients who were identified as such by positive PCR results, most of them showed fever or cough as the primary clinical signs. Less common symptoms observed in clinically confirmed cases were hemoptysis, bloody sputum, mental disorders, and nasal congestion. The most common clinical samples for PCR-confirmed COVID-19 patients were obtained from throat, oropharyngeal, and nasopharyngeal swabs, while tears and conjunctival secretions seem to be the least common clinical samples for COVID-19 diagnosis among studies. Also, different conserved SARS-CoV-2 gene sequences could be targeted for qRT-PCR detection. The suggested molecular assay being used by most laboratories for the detection of SARS-CoV-2 is qRT-PCR. Conclusion. There is a worldwide concern on the COVID-19 pandemic and a lack of well-managed global control. Hence, it is crucial to update the molecular diagnostics protocols for handling the situation. This is possible by understanding the available advances in assays for the detection of the SARS-CoV-2 infection. Good sampling procedure and using samples with enough viral loads, also considering the 
onset symptoms, may reduce the qRT-PCR false-negative results in symptomatic COVID-19 patients. Selection of the most efficient primer-probe for target genes and samples containing enough viral loads to search for the existence of SARS-CoV-2 helps detecting the virus on time using qRT-PCR.

\section{Introduction}

Coronaviruses are enveloped, nonsegmented, positive-sense RNA viruses. They belong to Coronaviridae and Coronavirinae, which are divided into four genera, namely, alpha, beta, gamma, and delta coronaviruses [1]. The genus Betacoronavirus comprises five subgenera including Embecovirus, Sarbecovirus, Merbecovirus, Nobecovirus, and Hibecovirus [2]. On March 2, 2020, a coronaviridae study group of the international committee on taxonomy of viruses (ICTV) declared their decision regarding the change of the name of the novel coronavirus (formerly known as 2019$\mathrm{nCoV}$ ) to severe acute respiratory syndrome corona virus 2 (SARS-CoV-2) which is accountable for the COVID-19 pandemic [3]. Coronaviruses did not require serious considerations before the SARS-CoV outbreak in 2002 [4], since they mainly cause common cold and diarrhea [5]. Subsequent to the SARS-CoV outbreak in 2002, there was another coronavirus outbreak in 2012, i.e., MERS-CoV [6]. MERS$\mathrm{CoV}$ was first isolated from a 60-year-old man from Saudi Arabia (previously known as HCoV-EMC) [7] and including the last reported case on February 17, 2020, when the World Health Organization (WHO) declared that there were 2521 laboratory-confirmed cases with 866 deaths $(34.4 \%$ case fatality rate) [8]. Different diseases which cause pneumonia often have the same symptoms, which makes it hard to determine the exact cause of the disease in order to start medication, and the disease caused by SARS-CoV-2 is not an exception. The main symptoms for COVID-19 are reported to be fever and fatigue, followed by sore throat and dyspnea and even, in some cases, neurological symptoms [9-11]. As the knowledge about coronaviruses causing diseases in humans was insufficient in 2002, the early diagnostic tests for SARS-CoV were not wholly reliable. The advances toward a more sensitive molecular method have solved the problem. Not only is the procedure itself of importance but also the types of the specimen prepared for the tests were. For instance, nasal wash specimens, throat swabs, and sputum were better at the onset of the infection [12]. The criterion for considering a patient as a SARS-CoV-infected case was the body temperature of more than $37.5 \mathrm{C}$ and having a nonproductive cough or dyspnea. The mainstay of confirmed diagnoses was the reverse transcriptase-polymerase chain reaction (RT-PCR) along with positive acute or serology tests [13-15]. RT-PCR has also been used for confirmation of MERS-CoV cases [16]. The WHO announced that regular confirmation of COVID-19 cases is possible by analyzing RT-R-PCR results of N, E, S, and RdRp genes (unique genes) [17]. The biosensor techniques can help COVID-19 diagnosis [18]. According to the previous infections by SARS-CoV and MERS-CoV, it is of importance to detect the SARS-CoV-2-infected individuals early to hinder the further spread of the virus, and it could be managed by utilizing the most beneficial detecting method along with the right sample. Also, using the most sufficient gene for RT-real-time PCR (as the molecular method) and considering the onset symptoms is of great importance in the process of detecting the infected patients. This study aims to point out the importance of clinical manifestations, detection methods of SARS-CoV2, and also timing and the types of samples in better detection of infected individuals with the aim of restricting the spread of the virus.

\section{Materials and Methods}

2.1. Data Sources and Search Strategies. We conducted a systematic literature review using Web of Science, Medline/ PubMed, Scopus, and EMBASE according to the PRISMA guideline [19]. The survey was concluded from 1 January 2020 until the end of April 2020. Three different researchers independently reviewed the search results. According to medical subject headings $(\mathrm{MeSH})$, the following search keywords were used: "Novel coronavirus 2019," “2019 nCoV," "COVID-19," Coronavirus disease 2019," "Wuhan coronavirus," "SARS-CoV-2," "severe acute respiratory syndrome coronavirus 2," "PCR," "Real-time PCR," "Symptoms," and "Clinical manifestation." The search results and study selection are shown in Figure 1.

2.2. Study Selection. Duplicate records were removed, and the results of the search were screened according to the titles and abstracts. In the next step, the English language full texts of articles were examined for inclusion and exclusion criteria (Figure 1). Articles that reported duplicate data from the same patients were excluded. The following articles with molecular data as well as clinical signs were selected in this study.

2.3. Data Collection Process and Data Items. The data extraction tables included information on the names of the authors, the number of patients, clinical symptoms (e.g., fever, cough, and fatigue), and molecular evaluation (e.g., sample type, PCR result, and target gene) which was extracted independently by three researchers. A fourth researcher screened the final data extraction list to prevent bias. Conflicts were decided by a fifth expert investigator.

2.4. Inclusion Criteria. We evaluated and included the published peer-review articles, which reported related clinical symptoms and the result of real-time reverse transcriptase-polymerase chain reaction (RRT-PCR) data for COVID-19 patients. For assessing clinical and molecular characteristics, eligible study designs such as series studies, case-control studies, and cohort studies were included. Article language limit was set on English, but we evaluated 


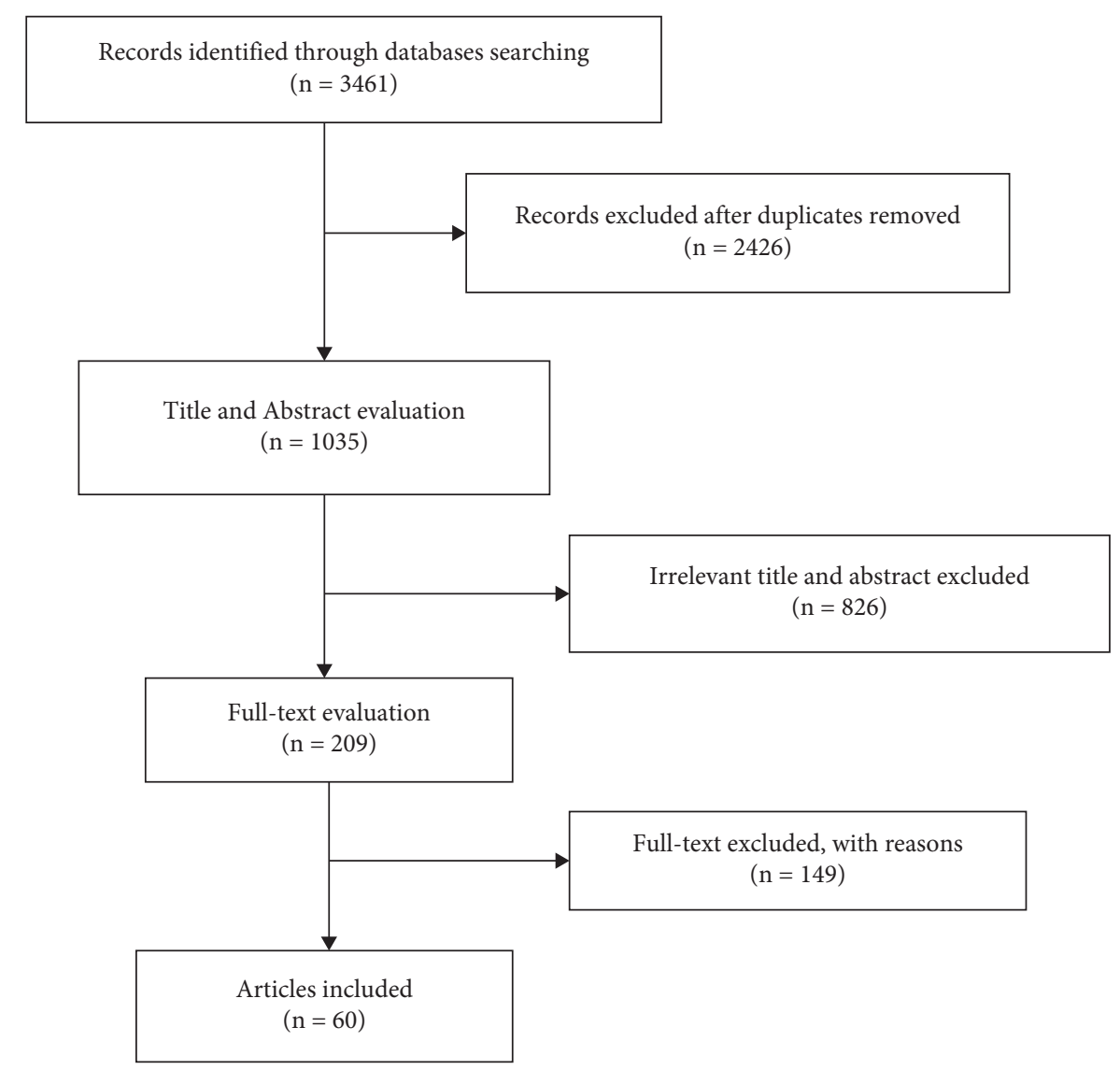

FIgURE 1: PRISMA 2009 flow diagram and summary of the literature search and study selection.

the non-English articles with essential data from their English abstracts.

2.5. Exclusion Criteria. Some studies were excluded due to the lack of relevant data or not meeting eligibility criteria. Articles which only assessed COVID-19 patients without molecular data were excluded. Literature reviews were screened for relevant citations, and letters to the editor, opinion articles, and case reports were excluded.

2.6. Quality Assessment. The quality of the chosen articles was evaluated using a checklist that covered the type of study, patients' number, sample type, real-time PCR result, target gene, data collection tools, and results analysis. Each article receives a score for the characteristic of a satisfactory methodology.

\section{Results}

In this section, we tried to mention the percentage of PCRconfirmed COVID-19 patients among the whole patients in the different enrolled studies and also tried to mention the results of molecular evaluation for detecting SARS-CoV-2 from the enrolled articles. We also mentioned the distribution of the different clinical manifestations among the confirmed patients. Then, we mentioned the results of our analysis about the different types of the samples and also the targeted genes that are used for the molecular detection of SARS-CoV-2 by RT-real-time PCR.

3.1. General and Demographic Data of Studies and Patients. The initial literature searching on databases collected 3461 articles. After checking the titles and abstracts and removing duplicate ones, 3252 citations were excluded. Finally, 60 articles met our inclusion criteria and were eligible for remaining in our systemic review. These articles were incorporated into the Endnote library for further investigations. The summary of the study selection strategy information is presented in Figure 1. A total of 60 articles were published in 2020. In 58 citations, both abstracts and full texts were in English while two studies had English abstracts and Chinese full texts.

Patients who suffered from COVID-19 show various types of symptoms. According to our screening of 60 selected articles, the highest prevalence rate was fever (100\%). The majority of the citations were conducted in China. The total number of patients involved in this investigation was 12946 (men and women) while 7643 of them were confirmed to be COVID-19 positive by molecular techniques, particularly the reverse transcription-polymerase chain reaction (RT-PCR) (Table 1).

3.2. Clinical Symptoms and Clinical Features of Patients. Patients who suffered from COVID-19 show various types of symptoms. According to our screening of 60 selected 


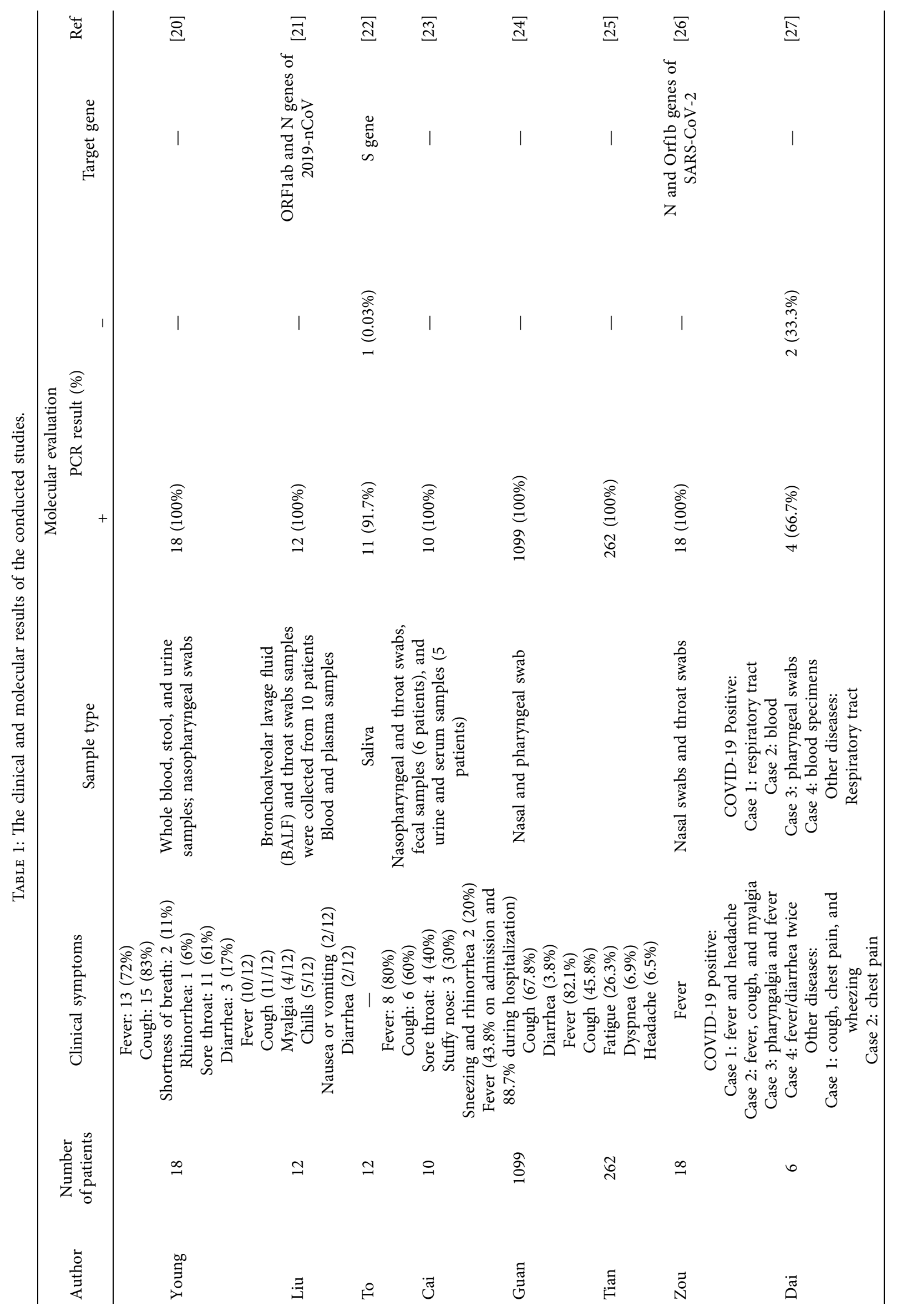




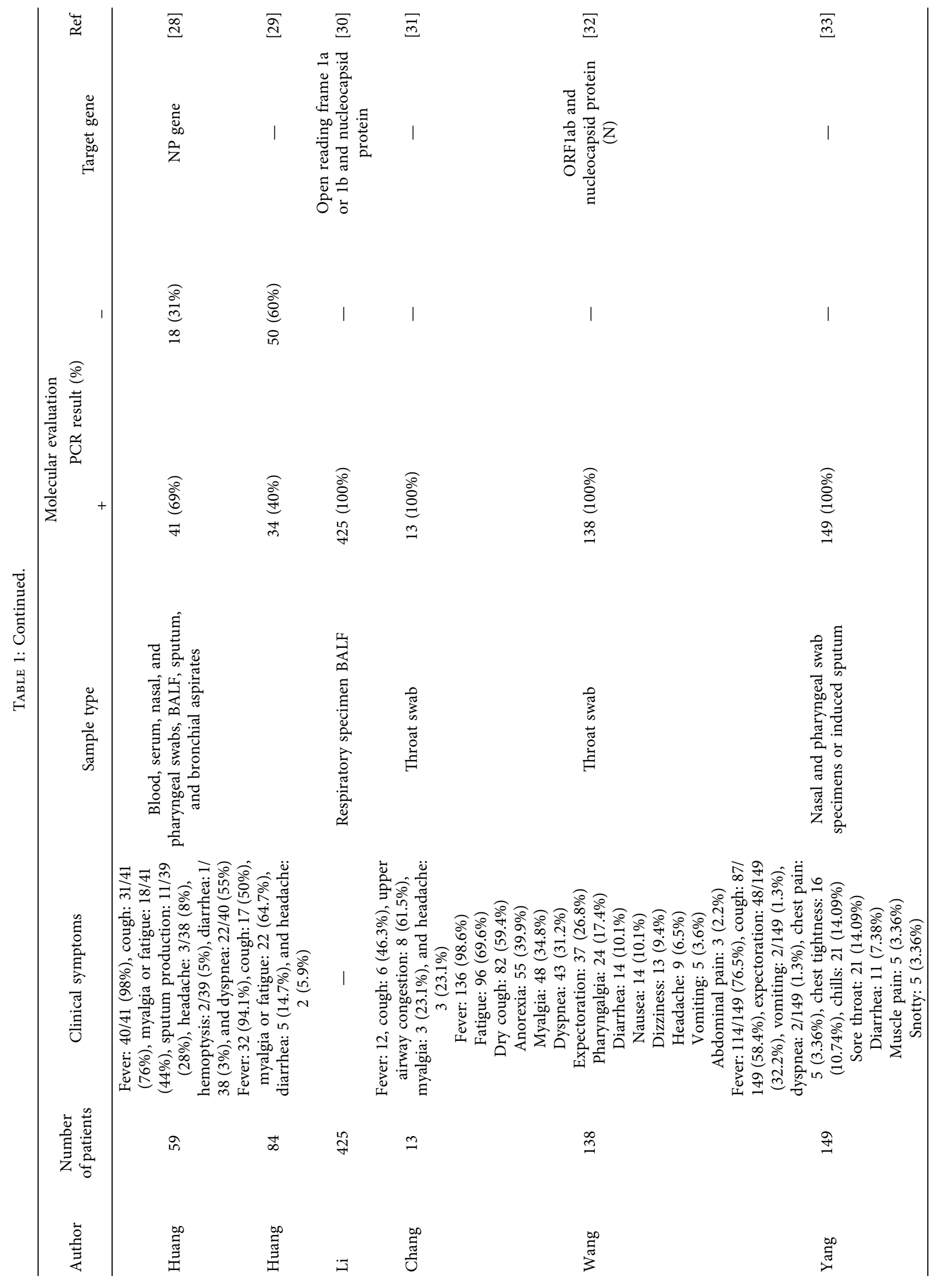




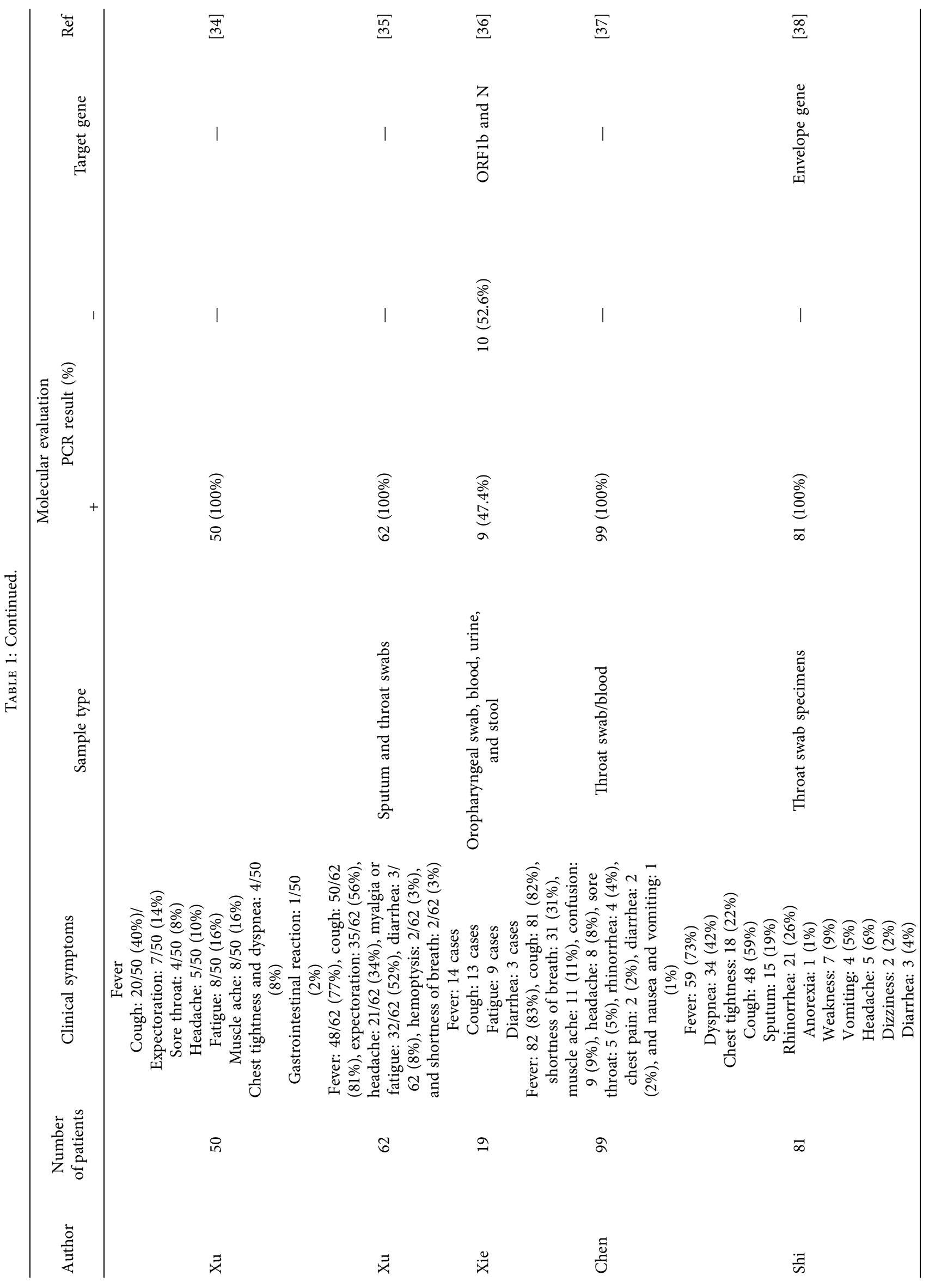




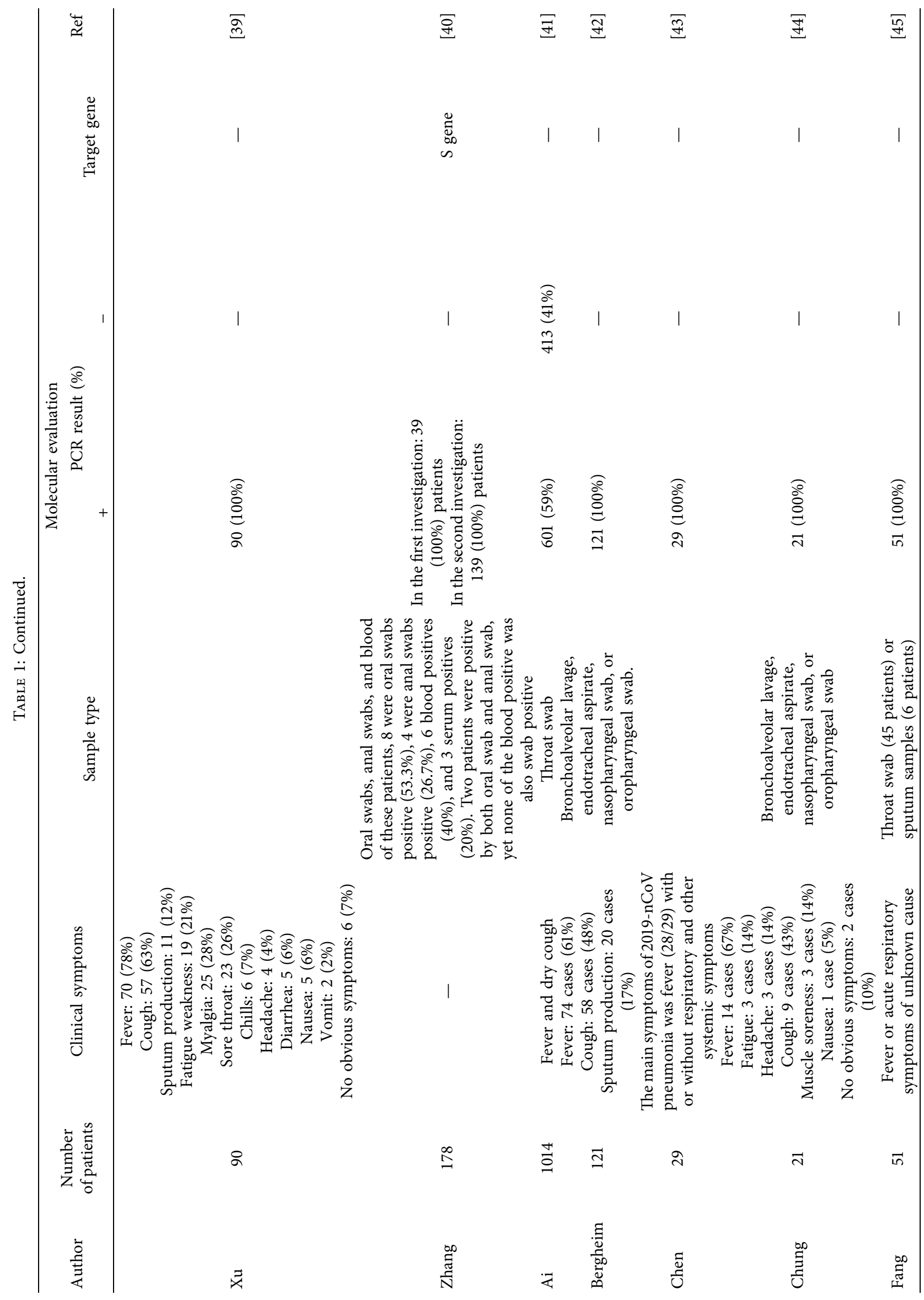




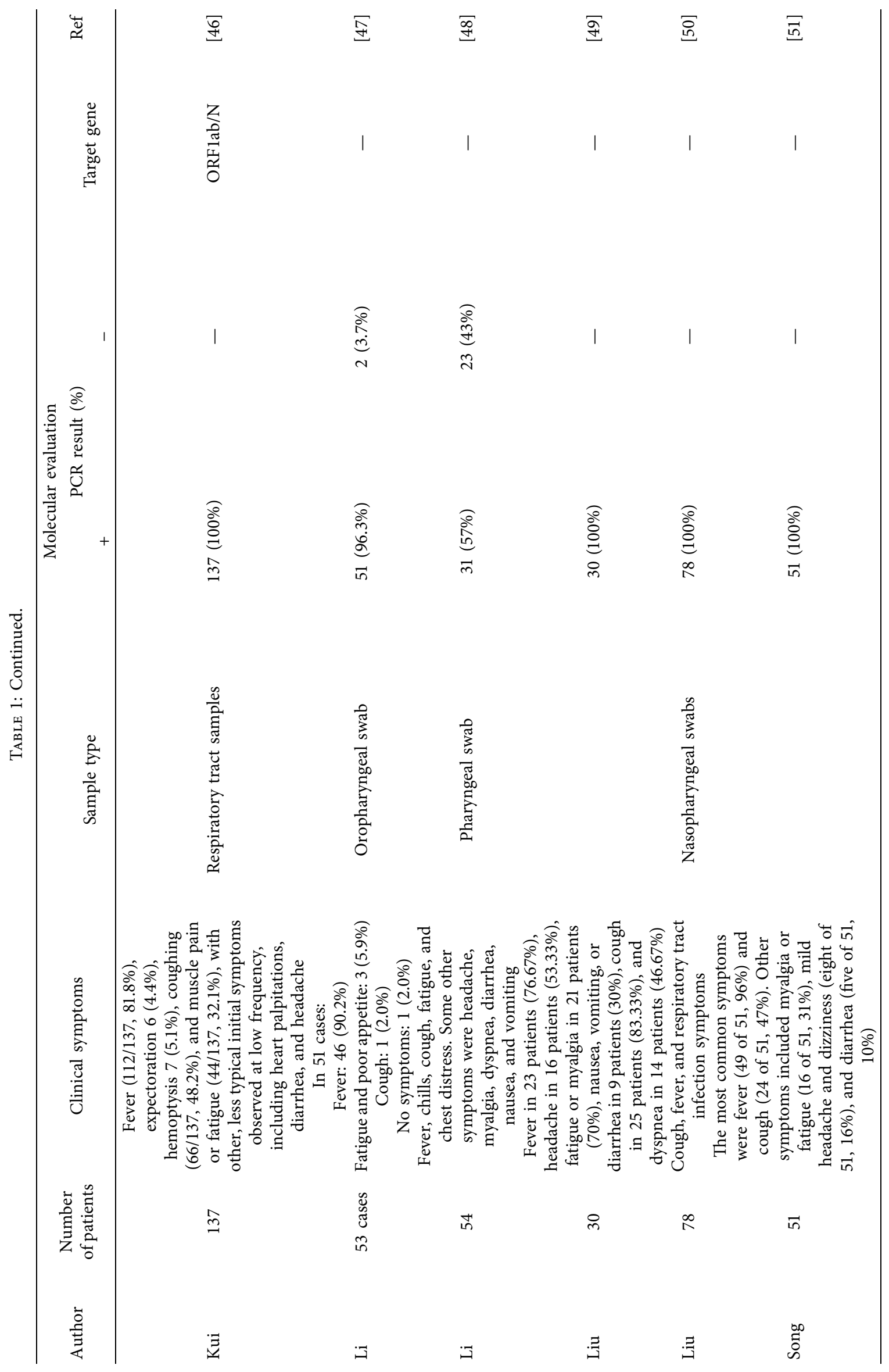




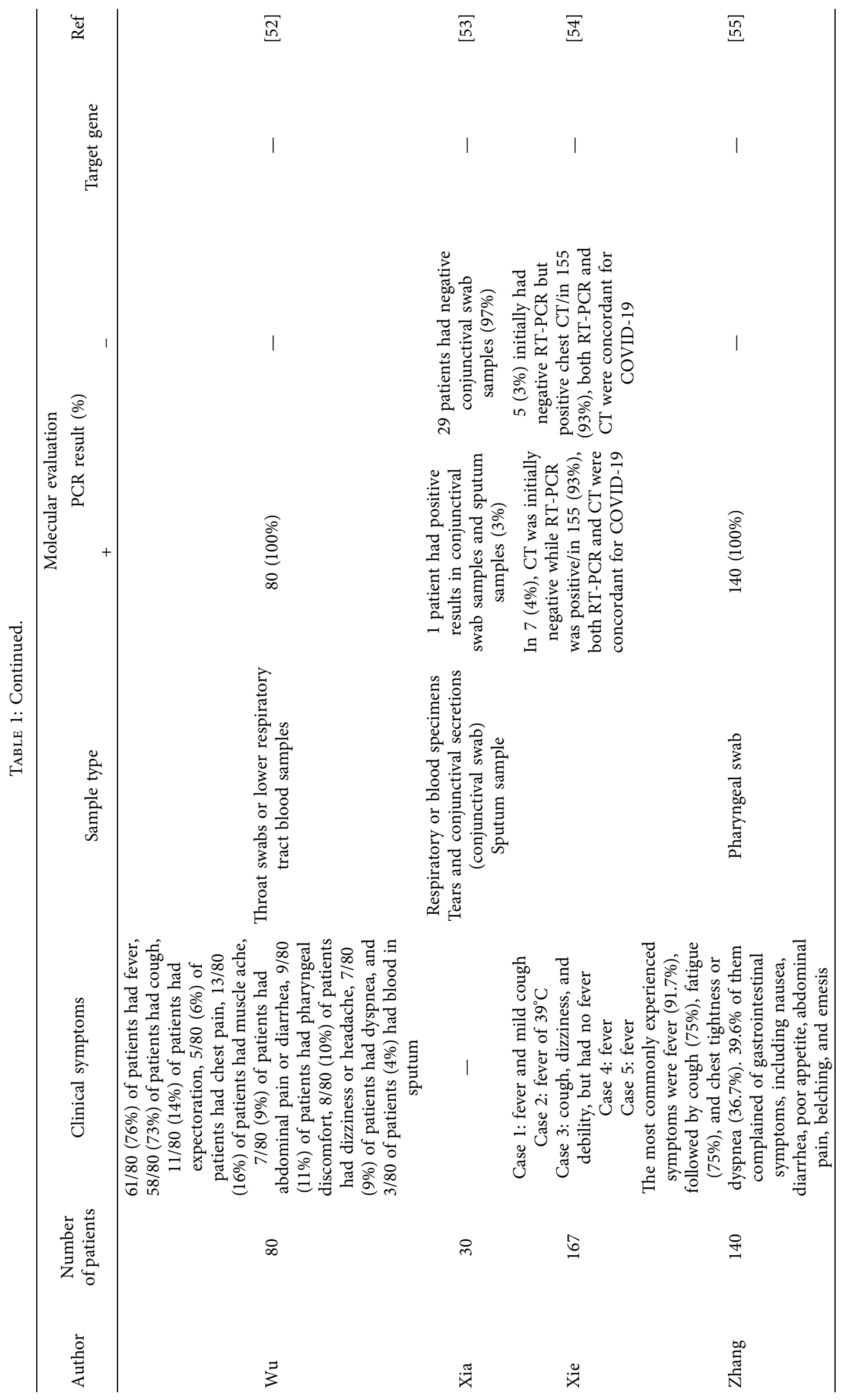




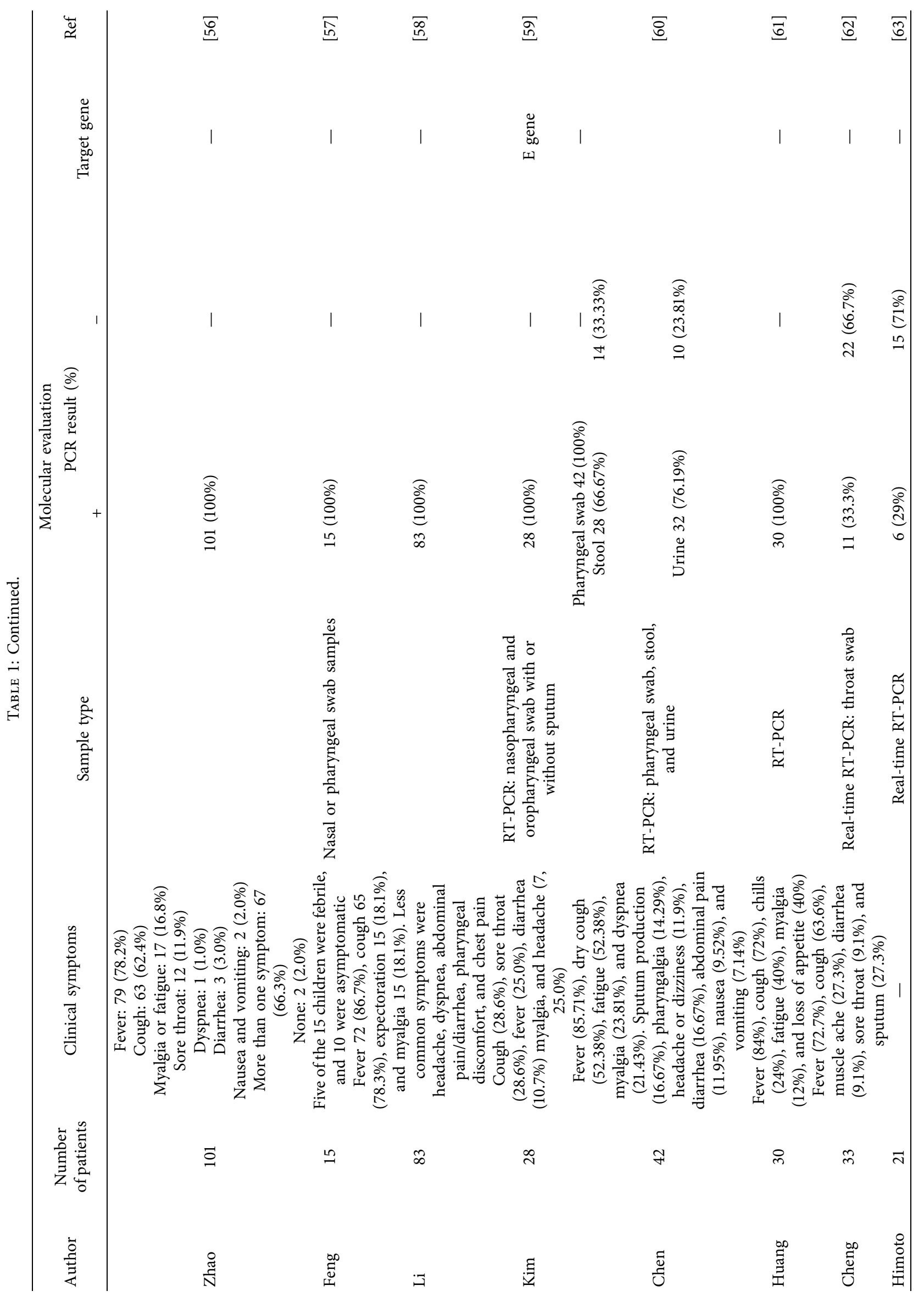




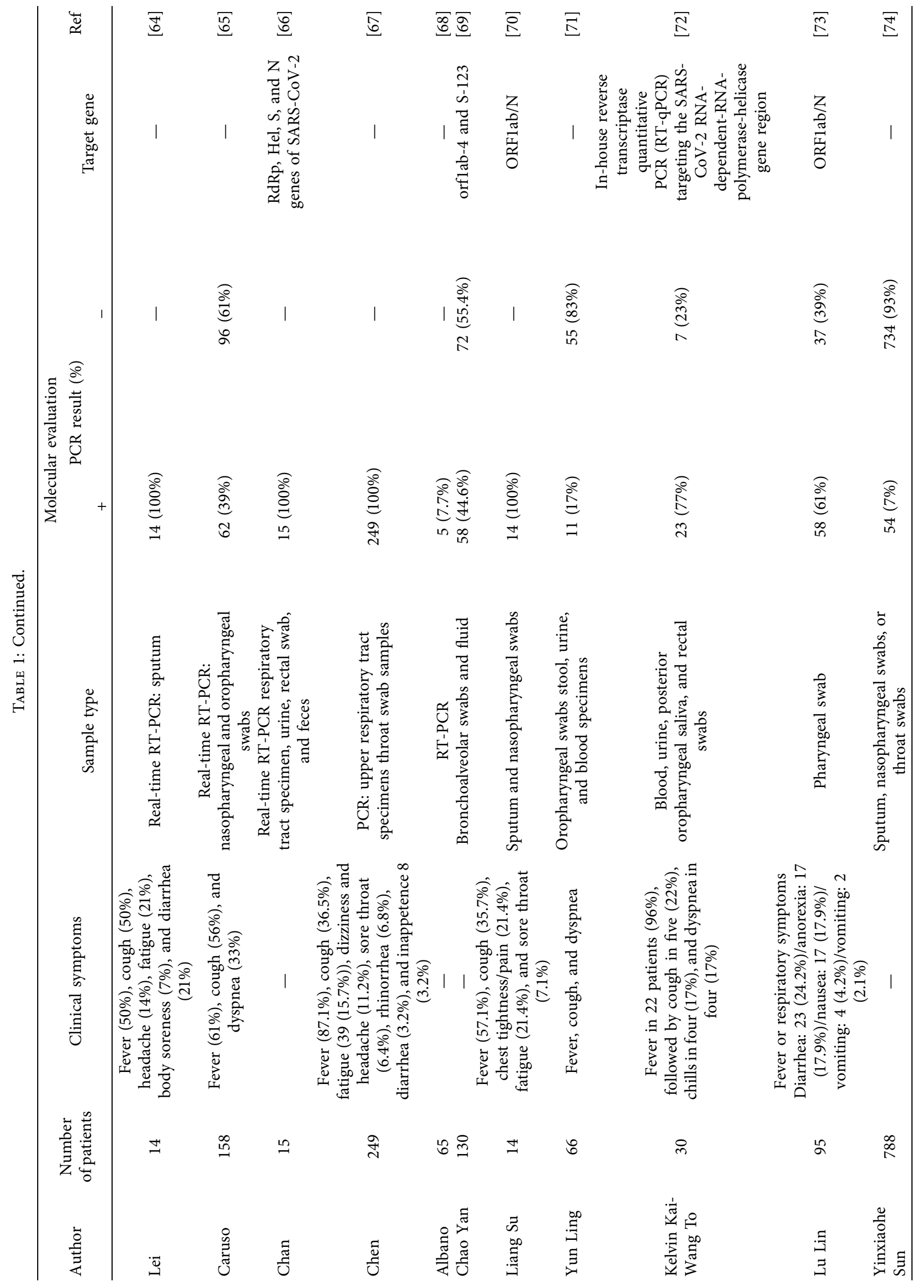




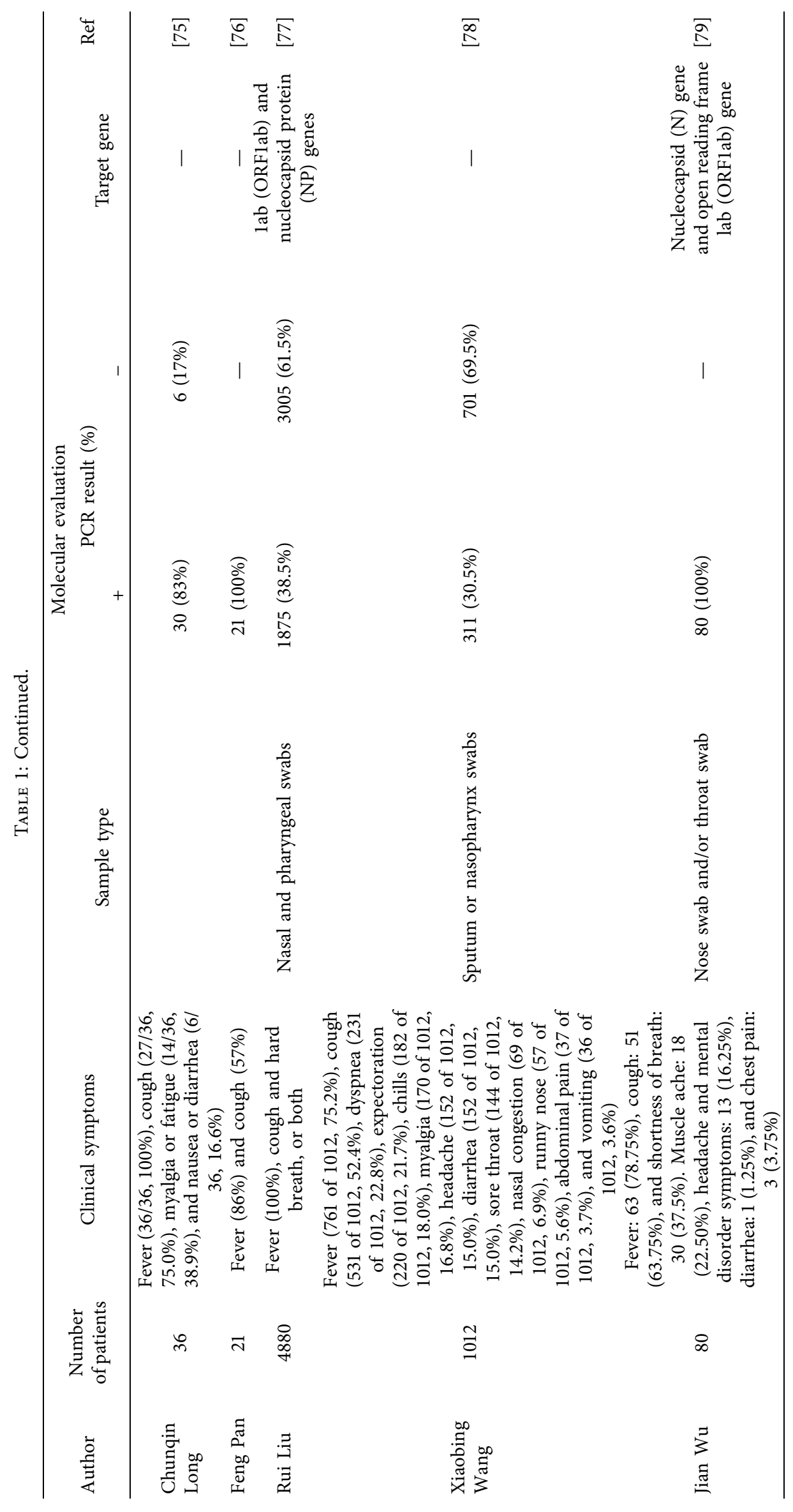


articles, the highest prevalence rate was of fever (100\%) [77], while the lowest was $25 \%$, and the prevalence rate of cough was $91 \%$ among 60 evaluated citations. The proportion of patients who had fatigue and myalgia ranged from $5.9 \%$ to $75 \%$ and $3.33 \%$ to $70 \%$, respectively. Chest pain/tightness was reported in 11 studies. Abdominal pain was documented in 6 studies, and mental disorders and confusion were observed in 2 citations only with $16.25 \%$ and $9 \%$ prevalence rate, respectively [37, 79]. In 7 studies, dizziness was a less common symptom in patients. Two studies reported nasal congestion by different rates of $61.5 \%$ and $6.9 \%$ [31, 78]. Other clinical symptoms such as shortness of breath (dyspnea), rhinorrhea, expectoration, chills and sore throat, nausea or vomiting, diarrhea, headache, and anorexia were less frequent in these studies. In 9 investigations, clinical manifestations were not documented.

\subsection{Molecular Evaluation (RT-Real-Time PCR) Results.} The RT-PCR results of 60 articles have been collected carefully. Several cohort and retrospective studies relied on RT-PCR results of other articles, and some conducted molecular evaluation by themselves. Among 12946 patients incorporated into our analysis, with 6 to 4880 patients per study, the COVID-19 RT-R-PCR assays of 7643 were positive. In most citations, all of the patients had 100\% positive results for molecular evaluation. In the other cases, a fluctuation in their PCR positivity rate reports was noted. Three studies had positive RT-PCR assays below $10 \%$ $[53,54,74]$. While 40 articles recorded positive results over a $90 \%$ rate, 17 citations declared their positivity proportion between 10 and $90 \%$.

3.4. RT-R-PCR Results and Clinical Symptoms. In almost all the citations which showed positivity in their PCR results, fever and cough were their main clinical manifestations while hemoptysis and blood in the sputum were the least common ones. Most of the positive cases experienced dyspnea, myalgia, nausea or vomiting, diarrhea, expectoration, chest pain, and headache. In one study, 4 out of 6 patients showed COVID-19 nucleic acid in their clinical samples; fever was their common symptom, while their other specific manifestations were cough, pharyngalgia, myalgia, and diarrhea [27]. The positivity rate of PCR was $96 \%$, and the patients showed poor appetite besides fever, cough, and fatigue [47]. Furthermore, in two other studies with $100 \%$ positivity in the presence of COVID-19 in the samples, poor appetite or loss of appetite were common symptoms among patients [55, 61]. Based on two studies with $100 \%$ and one study with $61 \%$ positive PCR results, anorexia was a common manifestation [32, 38, 73]. According to $\mathrm{Wu}$ et al., mental disorder was diagnosed among 13 out of 80 COVID-19 positive patients besides fever, cough, headache, muscle ache, diarrhea, and chest pain [79]. Furthermore, an article by Chen et al. revealed $100 \%$ positivity in the PCR results while confusion was observed with a $9 \%$ prevalence rate besides other symptoms [37].
3.5. RT-R-PCR Results and Sample Types. Various samples were obtained from different sites of patients' bodies for COVID-19 diagnosis. Regarding the PCR results with 100\% positivity for the presence of COVID-19 nucleic acid, the most common clinical samples were throat, oropharyngeal, and nasopharyngeal swabs. In three studies, all of the patients detected with COVID-19 [20, 23, 66] and four other studies with different prevalences of COVID-19-infected patients, urine samples were employed in their molecular assays and the positivity results had much fluctuation in comparison to each other. One citation with a 100\% PCR positivity rate [20] and 4 citations with different rates of positivity used stool samples to detect COVID-19 of their cases. In two studies with $77 \%$ and $91.7 \%$ positive PCR results, saliva was used for their molecular assay [22, 72]. Xia et al. worked on tears and conjunctival secretions of 30 COVID-19 positive patients, and their PCR results found only one patient had positive results in conjunctival swab samples [53]. In two citations, rectal swabs were collected for COVID-19 diagnosis and showed $100 \%$ and $77 \%$ PCR positive results [66, 72]. Five citations used bronchoalveolar lavage samples for molecular evaluation and the rate of COVID-19 prevalence in three of them was $100 \%[21,42,44]$, and two other results reported $69 \%$ and $44 \%[26,69]$. The study conducted by Chung et al. and Bergheim et al. on the endotracheal aspirates of patients were found to be COVID-19 positive by PCR assay.

Various studies that employed sputum samples in their molecular investigation revealed that most of them showed $100 \%$ positivity in the PCR results and only three studies had $69 \%, 30.5 \%$, and $7 \%$ positive prevalence rates.

3.6. RT-R-PCR Results and Target Gene. Different conserved SARS-CoV-2 gene sequences could be targeted for RT-PCR detection. In our systematic review analysis, 18 out of 60 included studies using several COVID-19 genes for diagnosing the presence of the virus nucleic acid in the samples of patients while more than half of the citations $(n=42)$ did not mention target genes for their PCR analysis. Nine citations used ORF1b [26, 36], and one study used ORF4 [69]. PCR target genes have different PCR positivity rates ranging from $38.5 \%$ to $100 \%$ per study. Based on 12 studies using the nucleocapsid $(\mathrm{N})$ sequence as the PCR-specific gene, 8 out of 12 studies found COVID-19 nucleic acid in all of their patients' samples. Four citations used spike (S) gene sequence as the PCR target. This gene was present in all of the samples of the patients in 2 studies [40, 66], and in two other studies, they found $44.6 \%$ and $91.7 \%$ PCR positivity rates $[22,69]$. Two studies revealed that envelope gene sequence was their target; all of the patients were infected with COVID-19 and showed positive results in the molecular assays [21,34]. Also, the RNA-dependent RNA-polymerase (RdRp) gene was the PCR specific gene with positive results $[22,66]$.

\section{Discussion}

4.1. A Lookback on Previous Members of Coronaviridae. SARS-CoV, MERS-CoV, and SARS-CoV-2 have proven to be threats against humans since they took so many lives 
during the past two decades. Other coronaviruses, such as HCoV-229E, HCoV0HKU1, HCoV-NL63, and HCoVOC43, are responsible for mild-to-moderate lower respiratory tract infections, including bronchiolitis and pneumonia [80]. HCoV-NL63 mostly causes illness in children and the elderly which has been shown to be associated with less than $10 \%$ of respiratory tract infections in children [81]. These viruses' fatality may not be like that of SARS-CoV and MERS-CoV and SARS-CoV-2. Nevertheless, it is crucial to detect the causative agent. To be able to control pathogens in order not to spread the viruses and risk any more lives, several diagnostic techniques were developed to take the situation under control. Before undergoing diagnostic testing, it was suggested that onset symptoms (i.e., fever, fatigue, cough, and dyspnea) and clinical features should be considered which are the most common along with pneumonia [82, 83]. In MERS-CoV cases, it was shown that, among three groups of patients, the ones exposed to the virus without any signs of pneumonia (group A) and patients with signs of pneumonia and respiratory failure (groups B and C, respectively), the ratio of patients with signs of lymphopenia was higher in group $\mathrm{C}$ compared to $\mathrm{B}$ and $\mathrm{A}(87.5 \%, 50.0 \%$, and $9.1 \%$ for groups $\mathrm{C}, \mathrm{B}$, and $\mathrm{A}$, respectively [84].

According to the WHO report, a suspected SARS case was for the first time described in 2003 with pneumonia which was supported by chest X-ray or a positive result by one or more assays (e.g., PCF, EKISA, and IF (A)) or autopsy results should be in accord with RDS pathology [85]. Despite a few amino acid differences in a few residues, including amino acids in the $8 \mathrm{~b}$ and $3 \mathrm{c}$ proteins, the receptor-binding domain (RBD) of SARS-CoV-2 is somewhat similar to that of SARS-CoV. Also, the primary protease is highly conserved between these two. These similarities alleviated the problems of developing new diagnostic assays which were already available for SARS-CoV [86]. The blood parameters and symptoms monitored are not accurate to determine the disease status. The most common target genes for the SARS$\mathrm{CoV}$ detection are nucleocapsid and polymerase (pol) genes [87]. The results should be normalized to the expression of internal control genes, including beta-actin and GADPH $[88,89]$.

4.2. Coronavirus Detection Methods and Different Types of Samples. Most citations included in this systematic review used the sequence of COVID-19 ORF genes in their investigations, and they accounted for the highest prevalence rate of COVID-19 infectivity in PCR assessments. Other genes of COVID-19 were employed in articles with various prevalence ranges of positivity in molecular tests. Despite the acceptance of RT-PCR as the main assay for confirmation of SARS-CoV infection, the sensitivity of RT-PCR is not as high as that of ELISA and IFA [90]. Ai et al. performed a study on 1014 cases with the purpose of indicating the correlation of chest CT and RT-PCR testing in COVID-19 patients. These scientists declared that, of 601 RT-PCRpositive COVID-19 patients, 580 were reported with positive CT scan results. In fact, Ai et al. suggested the sensitivity of
97\% for CT scan based on positive RT-PCR results [41]. In another study on 51 patients, the comparison of RT-PCR and chest CT showed a sensitivity of $71-98 \%$, respectively [45]. Above all, it seems pertinent to use a combination of molecular assays to achieve the integrity of the final results. Chest CT is also of great value for the detection of the onset of infection and observing its progress throughout the treatment [91]. After SARS-CoV's appearance in 2002, several assays were developed to detect the infection, i.e., fluorescent antibody detection, indirect ELISA, and RTPCR. The indirect ELISA results have a $2 \%$ false-positive range, and the infection can only be confirmed when there is a transition from seronegative to seropositive [92]. Seroconversion has reported to happen 28 days after infection onset in $93 \%$ of patients diagnosed with SARS.

Retrospective detection of the SARS-CoV is useless because there is no time to undergo treatment [93]. Molecular detection assays are good tools for confirmation of coronavirus infection because of their sensitivity and specificity provided that we are aware of false results due to the existence of inconstant viral loads and inaccuracy while samples are being prepared [94]. Nevertheless, highthroughput detection test assays such as next-generation sequencing were used for origin confirmation of SARS-CoV$2[95,96]$. There are several main reasons that justify the false-positive results of RT-PCR. First, at early stages after the disease onset, it is possible to get false-negative results from RT-R-PCR, and in that case, chest radiographs would be necessary to confirm the results [97]. Second, low viral load and laboratory errors might be playing a key role [54]. Specimen collection methods and choosing the right tissue for sample collection are also important in obtaining reliable results [28]. The suggested common specimens for the screening of SARS-CoV, MERS-CoV, and SARS-CoV-2 infections are frequently the same (i.e., nasopharyngeal and endotracheal aspirate, oropharyngeal saliva, and saliva) $[72,98-100]$. The sputum sample needs to be mixed with $2 \mathrm{~mL}$ of phosphate-buffered saline (PBS). Subsequently, RNA should be extracted using available RNA extraction kits or nucleic acid isolation kit $[101,102]$. In our analysis, the most common clinical samples among patients who were confirmed to be infected with COVID-19 is by PCR analysis were throat, oropharyngeal, and nasopharyngeal swabs while tears and conjunctival secretions seem to be the least common clinical sample for COVID - 19 diagnosis among these 60 studies. The suggested molecular assay is being used by most laboratories for the detection of SARS-CoV-2 is qRT-PCR. Both qualitative and quantitative real-time RTPCR are being applied as diagnostic tests for coronavirus infections [103, 104]. Quantitative real-time PCR (qRTPCR) and high-throughput sequencing are two routinely used nucleic acid testing assays that are suitable for SARSCoV-2. However, in comparison to high-throughput sequencing, qRT-PCR cost-effectiveness made it more common worldwide [105].

As SARS-CoV was the first coronavirus responsible for an outbreak in humans and because of the lack of insight into its genome, in most of the studies, the target genes used for PCR were segments of the POL1b coding region 
$[106,107]$. Open reading frames (ORFs) $1 \mathrm{a}$ and $1 \mathrm{~b}$ and the upstream of the envelope gene (upE) were used as targets for the detection of MERS-CoV $[8,100]$. The recommended target genes for SARS-CoV-2 infection screening using RTPCR mainly consist of orf1 ab and nucleocapsid protein (NP) genes [77, 108]. Several genes were suggested for screening, including RDRP, $\mathrm{E}$, and $\mathrm{N}$ genes [109]. Other minor coronaviruses (HCoV-229E, HCoV-HKU1, HCoV-NL63, and $\mathrm{HCoV}-\mathrm{OC} 43)$ have a low prevalence. Molecular detection of these viruses is based on the amplification of the membrane glycoprotein for $229 \mathrm{E}$ and OC43 and amplification of nucleocapsid protein for HKU1 and NL63 [80]. Notwithstanding the reported availability of COVID-19 PCR results, the lack of a clear correlation among qRT-PCR results, symptoms, sample types, and target genes is hindering the interpretation integrity of the PCR test results. That being said, recently, a new molecular detection method has been developed by Ishige et al. in which by the use of multiplex rRT-PCR, SARS-CoV-2 can be detected in clinical laboratories with high sensitivity. Not only does this method use two regions of the SARS-CoV-2 gene (E and N genes) for detection but also uses the human ABL1 gene as the inner control to evaluate the qualities of clinical specimens. In addition, these scientists mentioned that this method can diminish the usage of reagents and also it costs less [110]. Furthermore, despite the fact that detecting SARS-CoV-2 RNA in respiratory samples is considered to be the reference method, LO et al. proposed that utilizing both respiratory and fecal specimens can increase diagnostic sensitivity. As stool's viral load goes up in 2-3 weeks, meanwhile, SARSCoV-2 RNA may not be detectable through respiratory samples [111]. In line with this study, Tang et al. performed RT-PCR on both stool and respiratory tract samples of a 10year-old asymptomatic boy for detection of SARS-CoV-2 RNA and reported that, although RNA of SARS-CoV-2 was present in the stool sample, it was not detectable in the respiratory specimen [112].

4.3. Clinical Manifestations of COVID-19 Cases and Their Correlation with PCR Test Results. In this research letter, we attempted to gather the available data on PCR test results on COVID-19-suspected cases and summarize the significant trends. It is noteworthy to mention that, in 37 out of 60 articles, it showed positivity in all cases for the PCR test results. Considering the positive PCR results of suspected cases, the most prevalent observed symptoms include fever followed by cough which suggests that, during the time of the pandemic, patients who are showing these manifestations should be closely monitored until the real cause of the disease is determined $[20,21,25]$. Less common symptoms observed in clinically confirmed cases were hemoptysis, bloody sputum, mental disorders, and nasal congestion. These symptoms may be of low diagnostic value because of their frequency of presentation in COVID-19 cases. Nevertheless, it is of importance for its cause to undergo an investigation [52, 78, 79, 113]. Other frequent clinical manifestations including dyspnea, rhinorrhea, expectoration, chills, sore throat, nausea or vomiting, diarrhea, headache, and anorexia were also mentioned for SARSCoV-2 [20, 21, 24, 32, 38, 39, 73, 110]. Regarding the clinical symptoms of COVID-19, infected patients' fever and cough were the most prevalent clinical manifestations in each study, while mental disorders, confusion, nasal congestion, hemoptysis, and bloody sputum were the least common clinical symptoms reported in these 60 citations. Other common clinical symptoms which had different prevalent rates include shortness of breath (dyspnea), rhinorrhea, expectoration, chills and sore throat, nausea or vomiting, diarrhea, headache, and anorexia. Nine studies did not mention any clinical manifestations of the patients, and so, this conclusion is based on the studies that mentioned their patient's clinical symptoms. Given the relationship between the main clinical symptoms and PCR results, these 9 studies were not considered since no clinical observations were mentioned.

The false-negative test results impede control over spreading the disease. As it is asserted that a major reason for that to happen is the availability of inadequate viral load in tissue samples, considering the time of symptom onset, the selection of the right type of specimen is necessary [54]. In a study, it was mentioned that some patients had negative NAAT results from pharyngeal swabs but tested positive for SARS-CoV-2 from bronchoalveolar lavage [27]. Among the clinical samples used for the PCR assay which subsequently resulted positive for COVID-19, nasopharyngeal, oropharyngeal, and throat swabs were the most common ones and conjunctival secretions and tears were infrequent $[20,42,45,53]$. In 60 articles, 18 of them mentioned the target genes used for the PCR assay. In the majority of these articles, 11 employed ORF and nucleocapsid genes. These genes made a major contribution to the positive results retrieved from the PCR assays $[66,70,73,77]$. Other genes, including $S$ and $E$, were also used [40,59]. Also, the RdRp/Hel gene was targeted. [66]. Rare symptoms, including hemoptysis and bloody sputum, were associated with PCR-positive results when respiratory tract samples were prepared for the test $[52,113]$. Likewise, when fever and cough were the primary symptoms exerted on patients, the throat swab samples have a higher positivity rate in PCR test results $[26,31,32]$.

4.4. Available Treatments. It seems that the only way the COVID-19 pandemic can be controlled is the creation of an effective vaccine and development of novel antiviral drugs. Due to the fact that creation of new drugs and definitive treatments are time consuming, various clinical trials are currently underway to reposition available drugs to control the rate of infection. In this regard, several studies have been undertaken to establish the effectiveness of chloroquine and hydroxychloroquine (HCQ) in the treatment of COVID-19 infection [114, 115]. Gautret et al. reported that administration of hydroxychloroquine, which can be reinforced by azithromycin, can decrease the viral load in 3 to 6 days after administration. The results suggest that this combination can reduce the viral load and consequently limit the transmission of the virus to other people which may lead to the reduction of COVID-19 infection rate [116]. In addition, 
Wang et al. showed that remdesivir (a new antiviral drug) and chloroquine can play important roles in the control of COVID-19 infection in vitro [117]. In agreement with this study, Grain et al. conducted a cohort study to find out whether remdesivir is an effective treatment for severe COVID-19 patients or not, and clinical improvements was observed in $36 / 53(68 \%)$ of patients [118]. According to a study reported by the U.S. National Institute of Allergy and Infectious Diseases (NIAID), remdesivir was associated with a $31 \%$ "faster time to recovery." In this study, about $50 \%$ of people who received remdesivir were relieved from the hospital after 11 days vs. 15 days for people who received placebo. The death rate was also reduced among people who received remdesivir $(8 \%)$ vs. placebo $(11 \%)$. This result, while encouraging, was not statistically significant [119]. Apart from these investigations, Luo et al. suggested that tocilizumab can be a good choice for treatment of COVID-19 patients with the risk of cytokine storm and also repeated dose of tocilizumab is recommended for patients with escalated IL-6 rate [120]. After all, a reliable and sensitive detection technique combined with effective treatment strategies can alleviate the infection rate of COVID-19.

4.5. Gene Mutations Should Be Considered. Beside all the abovementioned findings in molecular detection methods and the type of specimens, gene mutations of the virus should also be considered, as recent reports have indicated a number of mutations in the SARS-CoV-2 genome [121-124]. SARSCoV-2's spike (S) protein, which consists of two domains called S1 and S2, is the most predominant contributor to the infection of target cells, by using ACE-2 as its main receptor. S1 plays an important role in the receptor binding, while S2 mediates subsequent membrane fusion [125-127]. D614G is one of these recent mutations, which has been shown to be increased over time. Also, this mutation is located in the C-terminal regain of the S1 domain [121, 128]. Zhang et al. analysis demonstrated that although D614G mutation was not observed in February (among 33 sequences), it was increasingly detectable through April (65\%) and May (70\%). In addition, these scientists also noted that this mutation in SARS-CoV-2's spike protein contributes to the increases in transmissibility of the virus [129]. Moreover, it has been shown that the mentioned mutation can result in escalations of viral loads in SARS-CoV-2-infected individuals [121].

\section{Conclusions}

Among the COVID-19 patients who had confirmed positive PCR results, most of them showed fever or cough as the major clinical signs; diarrhea, headache, and fatigue were less common between COVID-19 patients. Throat, oropharyngeal, and nasopharyngeal swabs were the most common clinical samples using PCR-confirmed COVID-19 patients. Since the SARS-CoV-2 pandemic has caused worldwide concern and the lack of a well-managed global control over the situation has caused many deaths, it is crucial to update the molecular diagnostics guidelines for handling the situation. That is possible by gaining an understanding of the available advances on assays for the detection of SARS-CoV-2 infection. The capability of these assays, including RT-R-PCR, to provide correct results is not at full potential, and the falsenegative results may make it harder to control the situation. However, the selection of the most efficient primer-probe for target genes and samples containing enough viral loads to search for the existence of SARS-CoV-2 helps detecting the virus on time. Despite the fact that the spread of the pandemic has been hindered to some extent and the world restriction measurements have been advanced to the vaccination and treatment stage, the sufficiency of the vaccines and treatments is yet to be understood. So, early detection of infected individuals is still the key to the restriction of the pandemic. The results of this study pointed out the importance of the criteria (i.e., using RT-real-time PCR as the detection method, most reliable samples, and the onset symptoms) and that considering them can lead to early detection of the infected patients and management of the crisis.

\section{Data Availability}

The data are available from Jonathan R. Dimmock on reasonable request.

\section{Ethical Approval}

This article does not contain any studies with human participants or animals performed by any of the authors.

\section{Conflicts of Interest}

The authors have no conflicts of interest.

\section{Authors' Contributions}

Saber Soltani and Jonathan R. Dimmock conceptualized and designed the review. Saber Soltani, Jonathan R. Dimmock, Milad Zandi, and Abbas Farahani interpretated data for the work, wrote the manuscript, and provided final approval of the version to be published. Armin Zakeri, Sara Akhavan Rezayat, Ramin Mohammadi, Umashankar Das, Shervin Afzali, Mohammadvala Ashtar Nakhaei, Alireza Doroudi, and Yousef Erfani collected data and wrote the manuscript. Saber Soltani, Jonathan R. Dimmock, and Abbas Farahani supervised the collection of the data and wrote the manuscript. All authors reviewed and approved the manuscript. Abbas Farahani and Milad Zandi are co-first authors.

\section{Acknowledgments}

Maunders McNeil Foundation Inc. is thanked for providing funding to Dr. Dimmock. Ethical consideration was earned from the Tehran University of Medical Sciences, Iran (no: 47289, code of ethics: IR.TUMS.VCR.REC.1399.049).

\section{References}

[1] S. Anthony, R. Ojeda-Flores, O. Rico-Chávez, and I. Navarrete-Macias, "Coronaviruses in bats from Mexico," Journal of General Virology, vol. 94, pp. 1028-1038, 2020. 
[2] M. Zandi and S. Soltani, "Hemagglutinin-esterase cannot be considered as a candidate for designing drug against COVID-19," Molecular Diversity, vol. 25, pp. 1999-2000, 2021.

[3] Coronaviridae Study Group of the International Committee on Taxonomy of Viruses, "The species severe acute respiratory syndrome-related coronavirus: classifying 2019-nCoV and naming it SARS-CoV-2," Nature Microbiology, vol. 5, pp. 536-544, 2020.

[4] M. Bolles, E. Donaldson, and R. Baric, "SARS-CoV and emergent coronaviruses: viral determinants of interspecies transmission," Current Opinion in Virology, vol. 1, no. 6, pp. 624-634, 2011.

[5] M. M. C. Lai, "Corona virus: organization, replication and expression of genome," Annual Review of Microbiology, vol. 44, no. 1, p. 303, 1990.

[6] S. Zúñiga-Lucas, F. J. Gutierrez-Alvarez, and R. FernandezDelgado, "Role of middle east respiratory syndrome coronavirus protein 5 on pathogenesis revealed using an engineered mouse-adapted reverse genetics system," 2019.

[7] A. M. Zaki, S. van Boheemen, T. M. Bestebroer, A. D. M. E. Osterhaus, and R. A. M. Fouchier, "Isolation of a novel coronavirus from a man with pneumonia in Saudi Arabia," New England Journal of Medicine, vol. 367, no. 19, pp. 1814-1820, 2012.

[8] World Health Organization, Middle East Respiratory Syndrome Coronavirus (MERS-CoV)-Qatar, World Health Organization, Geneva, Switzerland, 2020, https:// www.who.int/csr/don/12-march-2020-mers-qatar/en/.

[9] X. Yang, Y. Yu, J. Xu et al., "Clinical course and outcomes of critically ill patients with SARS-CoV-2 pneumonia in Wuhan, China: a single-centered, retrospective, observational study," The Lancet Respiratory Medicine, vol. 8, no. 5, pp. 475-481, 2020.

[10] L. Pan, M. Mu, P. Yang et al., "Clinical characteristics of COVID-19 patients with digestive symptoms in Hubei, China: a descriptive, cross-sectional, multicenter study," American Journal of Gastroenterology, vol. 115, no. 5, pp. 766-773, 2020.

[11] S. Soltani, A. Tabibzadeh, A. Zakeri et al., "COVID-19 associated central nervous system manifestations, mental and neurological symptoms: a systematic review and metaanalysis," Reviews in the Neurosciences, vol. 32, no. 3, pp. 351-361, 2021.

[12] K. H. Chan, L. L. L. M. Poon, V. C. C. Cheng et al., "Detection of SARS coronavirus in patients with suspected SARS," Emerging Infectious Diseases, vol. 10, no. 2, pp. 294-299, 2004.

[13] M. P. Muller, S. E. Richardson, A. McGeer et al., "Early diagnosis of SARS: lessons from the Toronto SARS outbreak," European Journal of Clinical Microbiology \& Infectious Diseases, vol. 25, no. 4, pp. 230-237, 2006.

[14] K. W. Choi, T. N. Chau, O. Tsang et al., "Outcomes and prognostic factors in 267 patients with severe acute respiratory syndrome in Hong Kong," Annals of Internal Medicine, vol. 139, no. 9, pp. 715-723, 2003.

[15] P. K. S. Chan, K.-C. Ng, R. C. W. Chan et al., "Immunofluorescence assay for serologic diagnosis of SARS," Emerging Infectious Diseases, vol. 10, no. 3, pp. 530-532, 2004.

[16] S. Al Johani and A. H. Hajeer, "MERS-CoV diagnosis: an update," Journal of Infection and Public Health, vol. 9, no. 3, pp. 216-219, 2016.
[17] World Health Organization, Laboratory Testing for 2019 Novel Coronavirus (2019- $n$ CoV) in Suspected Human Cases 2020, World Health Organization, Geneva, Switzerland, 2019, https://www.who.int/publications-detail/laboratorytesting-for-2019-novel-coronavirus-in-suspected-humancases-20200117.

[18] M. Fani, M. Zandi, S. Soltani, and S. Abbasi, "Future developments in biosensors for field-ready SARS-CoV-2 virus diagnostics," Biotechnology and Applied Biochemistry, vol. 68, pp. 695-699, 2020.

[19] D. Moher, A. Liberati, J. Tetzlaff, and D. G. Altman, "Preferred reporting items for systematic reviews and metaanalyses: the PRISMA statement," PLoS Medicine, vol. 6, no. 7, Article ID e1000097, 2009.

[20] B. E. Young, S. W. X. Ong, S. Kalimuddin et al., "Epidemiologic features and clinical course of patients infected with SARS-CoV-2 in Singapore," JAMA, vol. 323, no. 15, pp. 1488-1494, 2020.

[21] Y. Liu, Y. Yang, C. Zhang et al., "Clinical and biochemical indexes from 2019-nCoV infected patients linked to viral loads and lung injury," Science China Life Sciences, vol. 63, no. 3, pp. 364-374, 2020.

[22] K. K.-W. To, "Consistent detection of 2019 novel coronavirus in saliva," Clinical Infectious Diseases, vol. 71, no. 15, pp. 841-843, 2020.

[23] J. Cai, X. Jin, L. Daojiong, and Y. Zhi, "A case series of children with 2019 novel coronavirus infection: clinical and epidemiological features," Clinical Infectious Diseases, vol. 71, no. 6, pp. 1547-1551, 2020.

[24] W.-j. Guan, Z.-y. Ni, Y. Hu et al., "Clinical characteristics of coronavirus disease 2019 in China," New England Journal of Medicine, vol. 382, no. 18, pp. 1708-1720, 2020.

[25] S. Tian, N. Hu, J. Lou et al., "Characteristics of COVID-19 infection in Beijing," Journal of Infection, vol. 80, no. 4, pp. 401-406, 2020.

[26] L. Zou, F. Ruan, M. Huang et al., "SARS-CoV-2 viral load in upper respiratory specimens of infected patients," New England Journal of Medicine, vol. 382, no. 12, pp. 1177-1179, 2020.

[27] W.-c. Dai, H.-w. Zhang, J. Yu et al., "CT imaging and differential diagnosis of COVID-19," Canadian Association of Radiologists Journal, vol. 71, no. 2, pp. 195-200, 2020.

[28] C. Huang, Y. Wang, X. Li et al., "Clinical features of patients infected with 2019 novel coronavirus in Wuhan, China," The lancet, vol. 395, no. 10223, pp. 497-506, 2020.

[29] Y. Huang, "Clinical characteristics of laboratory confirmed positive cases of SARS-CoV-2 infection in Wuhan, China: a retrospective single center analysis," Travel Medicine and Infectious Disease, vol. 36, Article ID 101606, 2020.

[30] Q. Li, X. Guan, P. Wu et al., "Early transmission dynamics in Wuhan, China, of novel coronavirus-infected pneumonia," New England Journal of Medicine, vol. 382, no. 13, pp. 1199-1207, 2020.

[31] D. Chang, M. Lin, L. Wei et al., "Epidemiologic and clinical characteristics of novel coronavirus infections involving 13 patients outside Wuhan, China," Jama, vol. 323, no. 11, pp. 1092-1093, 2020.

[32] D. Wang, B. Hu, C. Hu et al., "Clinical characteristics of 138 hospitalized patients with 2019 novel coronavirus-infected pneumonia in Wuhan, China," JAMA, vol. 323, no. 11, pp. 1061-1069, 2020.

[33] W. Yang, Q. Cao, L. Qin et al., "Clinical characteristics and imaging manifestations of the 2019 novel coronavirus disease (COVID-19):A multi-center study in Wenzhou city, 
Zhejiang, China," Journal of Infection, vol. 80, no. 4, pp. 388-393, 2020.

[34] Y.-H. Xu, J.-H. Dong, W.-M. An et al., "Clinical and computed tomographic imaging features of novel coronavirus pneumonia caused by SARS-CoV-2," Journal of Infection, vol. 80, no. 4, pp. 394-400, 2020.

[35] X. W. Xu, "Clinical findings in a group of patients infected with the 2019 novel coronavirus (SARS-Cov-2) outside of Wuhan, China: retrospective case series," BMJ, vol. 368, 2020.

[36] C. Xie, L. Jiang, G. Huang et al., "Comparison of different samples for 2019 novel coronavirus detection by nucleic acid amplification tests," International Journal of Infectious Diseases, vol. 93, pp. 264-267, 2020.

[37] N. Chen, M. Zhou, X. Dong et al., "Epidemiological and clinical characteristics of 99 cases of 2019 novel coronavirus pneumonia in Wuhan, China: a descriptive study," The Lancet, vol. 395, no. 10223, pp. 507-513, 2020.

[38] H. Shi, X. Han, N. Jiang et al., "Radiological findings from 81 patients with COVID-19 pneumonia in Wuhan, China: a descriptive study," The Lancet Infectious Diseases, vol. 20, no. 4, pp. 425-434, 2020.

[39] X. Xu, C. Yu, J. Qu et al., "Imaging and clinical features of patients with 2019 novel coronavirus SARS-CoV-2," European Journal of Nuclear Medicine and Molecular Imaging, vol. 47, no. 5, pp. 1275-1280, 2020.

[40] W. Zhang, R.-H. Du, B. Li et al., "Molecular and serological investigation of 2019-nCoV infected patients: implication of multiple shedding routes," Emerging Microbes \& Infections, vol. 9, no. 1, pp. 386-389, 2020.

[41] T. Ai, "Correlation of chest CT and RT-PCR testing in coronavirus disease 2019 (COVID-19) in China: a report of 1014 cases," RSNA, vol. 7, 2020.

[42] A. Bernheim, X Mei, M Huang et al., "Chest CT findings in coronavirus disease-19 (COVID-19): relationship to duration of infection," Radiology, vol. 295, no. 3, p. 200463, 2020.

[43] L. Chen, "Analysis of clinical features of 29 patients with 2019 novel coronavirus pneumonia," Chinese Journal of Tuberculosis and Respiratory Diseases, vol. 43, 2020.

[44] M. Chung, A. Bernheim, X. Mei et al., "CT imaging features of 2019 novel coronavirus (2019-nCoV)," Radiology, vol. 295, no. 1, pp. 202-207, 2020.

[45] Y. Fang, "Sensitivity of chest CT for COVID-19: comparison to RT-PCR,” RSNA, vol. 296, no. 2, pp. E115-E117, 2020.

[46] L. Kui, "Clinical characteristics of novel coronavirus cases in tertiary hospitals in Hubei Province," Chinese Medical Journal, vol. 133, pp. 1025-1031, 2020.

[47] Y. Li and L. Xia, "Coronavirus disease 2019 (COVID-19): role of chest $\mathrm{CT}$ in diagnosis and management," American Journal of Roentgenology, vol. 214, no. 6, pp. 1280-1286, 2020.

[48] YY. Li, "Comparison of the clinical characteristics between RNA positive and negative patients clinically diagnosed with 2019 novel coronavirus pneumonia," CJTRD, vol. 43, pp. 427-430, 2020.

[49] M. Liu, "Clinical characteristics of 30 medical workers infected with new coronavirus pneumonia," CJTRD, vol. 43, 2020.

[50] W. Liu, Z.-W. Tao, L. Wang et al., "Analysis of factors associated with disease outcomes in hospitalized patients with 2019 novel coronavirus disease," Chinese Medical Journal, vol. 133, no. 9, pp. 1032-1038, 2020.

[51] F. Song, "Emerging coronavirus 2019-nCoV pneumonia," RSNA, vol. 295, 2020.
[52] J. Wu, X. Wu, W. Zeng et al., "Chest CT findings in patients with coronavirus disease 2019 and its relationship with clinical features," Investigative Radiology, vol. 55, no. 5, pp. 257-261, 2020.

[53] J. Xia, J. Tong, M. Liu, Y. Shen, and D. Guo, "Evaluation of coronavirus in tears and conjunctival secretions of patients with SARS-CoV-2 infection," Journal of Medical Virology, vol. 92, no. 6, pp. 589-594, 2020.

[54] X. Xie, Z. Zhong, W. Zhao, C. Zheng, F. Wang, and J. Liu, "Chest CT for typical 2019-nCoV pneumonia: relationship to negative RT-PCR testing," RSNA, vol. 296, no. 2, pp. E41-E45, 2020.

[55] J.-j. Zhang, "Clinical characteristics of 140 patients infected with SARS-CoV-2 in Wuhan, China," The Journal of Allergy and Clinical Immunology, vol. 75, no. 7, pp. 1730-1741, 2020.

[56] W. Zhao, Z. Zhong, X. Xie, Q. Yu, and J. Liu, "Relation between chest CT findings and clinical conditions of coronavirus disease (COVID-19) pneumonia: a multicenter study," American Journal of Roentgenology, vol. 214, no. 5, pp. 1072-1077, 2020.

[57] K. Feng, "Analysis of CT features of 15 Children with 2019 novel coronavirus infection," Chinese Journal of Pediatrics, vol. 58, 2020.

[58] K. Li, J. Wu, F. Wu et al., "The clinical and chest CT features associated with severe and critical COVID-19 pneumonia," Investigative Radiology, vol. 55, no. 6, pp. 327-331, 2020.

[59] E. S. Kim, B. S. Chin, C. K. Kang, and N. J. Kim, "Clinical course and outcomes of patients with severe acute respiratory syndrome coronavirus 2 infection: a preliminary report of the first 28 patients from the Korean cohort study on COVID-19," Journal of Korean Medical Science, vol. 35, no. 13, 2020.

[60] Y. Chen, L. Chen, Q. Deng et al., "The presence of SARSCoV-2 RNA in the feces of COVID-19 patients," Journal of Medical Virology, vol. 92, no. 7, pp. 833-840, 2020.

[61] G. Huang, "Timely diagnosis and treatment shortens the time to resolution of coronavirus disease (COVID-19) pneumonia and lowers the highest and last CT scores from sequential chest CT," AJR, vol. 215, no. 2, pp. 367-373, 2020.

[62] Z. Cheng, "Clinical features and chest CT manifestations of coronavirus disease 2019 (COVID-19) in a single-center study in Shanghai, China," American Journal of Roentgenology, vol. 215, no. 1, pp. 121-126, 2020.

[63] Y. Himoto, A. Sakata, M. Kirita et al., "Diagnostic performance of chest CT to differentiate COVID-19 pneumonia in non-high-epidemic area in Japan," Japanese Journal of Radiology, vol. 38, no. 5, pp. 400-406, 2020.

[64] P. Lei, Z. Huang, G. Liu et al., "Clinical and computed tomographic (CT) images characteristics in the patients with COVID-19 infection: what should radiologists need to know?" Journal of X-Ray Science and Technology, vol. 28, no. 3, pp. 369-381, 2020.

[65] D. Caruso, "Chest CT features of COVID-19 in Rome, Italy," Radiology, vol. 296, no. 2, pp. E79-E85, 2020.

[66] J. F. Chan, C. C.-Y. Yip, K. K.-W. To, and T. H.-C. Tang, "Improved molecular diagnosis of COVID-19 by the novel, highly sensitive and specific COVID-19-RdRp/hel real-time reverse transcription-polymerase chain reaction assay validated in vitro and with clinical specimens," Journal of Clinical Microbiology, vol. 58, pp. 310-320, 2020.

[67] J. Chen, T. Qi, L. Liu et al., "Clinical progression of patients with COVID-19 in Shanghai, China," Journal of Infection, vol. 80, pp. e1-e6, 2020. 
[68] D. Albano, F. Bertagna, M. Bertoli et al., "Incidental findings suggestive of COVID-19 in asymptomatic patients undergoing nuclear medicine procedures in a high-prevalence region," Journal of Nuclear Medicine, vol. 61, no. 5, pp. 632-636, 2020.

[69] C. Yan, J. Cui, L. Huang et al., "Rapid and visual detection of 2019 novel coronavirus (SARS-CoV-2) by a reverse transcription loop-mediated isothermal amplification assay," Clinical Microbiology and Infection, vol. 26, no. 6, pp. 773779, 2020.

[70] L. Su, X. Ma, H. Yu et al., "The different clinical characteristics of corona virus disease cases between children and their families in China-the character of children with COVID-19," Emerging Microbes \& Infections, vol. 9, no. 1, pp. 707-713, 2020.

[71] Y. Ling, S.-B. Xu, Y.-X. Lin et al., "Persistence and clearance of viral RNA in 2019 novel coronavirus disease rehabilitation patients," Chinese Medical Journal, vol. 133, no. 9, pp. 1039-1043, 2020.

[72] K. K.-W. To, O. T.-Y. Tsang, W.-S. Leung et al., “Temporal profiles of viral load in posterior oropharyngeal saliva samples and serum antibody responses during infection by SARS-CoV-2: an observational cohort study," The Lancet Infectious Diseases, vol. 20, no. 5, pp. 565-574, 2020.

[73] L. Lin, X. Jiang, Z. Zhang et al., "Gastrointestinal symptoms of 95 cases with SARS-CoV-2 infection," Gut, vol. 69, no. 6, pp. 997-1001, 2020.

[74] Y. Sun, "Epidemiological and clinical predictors of COVID19," Clinical Infectious Diseases: An Official Publication of the Infectious Diseases Society of America, vol. 71, no. 15, pp. 786-792, 2020.

[75] C. Long, "Diagnosis of the coronavirus disease (COVID-19): rRT-PCR or CT?” European Journal of Radiology, vol. 126, Article ID 108961, 2020.

[76] F. Pan, "Time course of lung changes on chest CT during recovery from 2019 novel coronavirus (COVID-19) pneumonia," RSNA, vol. 295, 2020.

[77] R. Liu, H. Han, F. Liu et al., "Positive rate of RT-PCR detection of SARS-CoV-2 infection in 4880 cases from one hospital in Wuhan, China, from Jan to Feb 2020," Clinica Chimica Acta, vol. 505, pp. 172-175, 2020.

[78] X. Wang, J. Fang, Y. Zhu, and L. Chen, "Clinical characteristics of non-critically ill patients with novel coronavirus infection (COVID-19) in a Fangcang hospital," CMI, vol. 26, no. 8, pp. 1063-1068, 2020.

[79] J. Wu, "Clinical characteristics of imported cases of COVID19 in Jiangsu province: a multicenter descriptive study," Clinical Infectious Diseases, vol. 29, 2020.

[80] E. R. Gaunt, A. Hardie, E. C. J. Claas, P. Simmonds, and K. E. Templeton, "Epidemiology and clinical presentations of the four human coronaviruses 229E, HKU1, NL63, and OC43 detected over 3 years using a novel multiplex real-time PCR method," Journal of Clinical Microbiology, vol. 48, no. 8, pp. 2940-2947, 2010.

[81] B. C. Fielding, "Human coronavirus NL63: a clinically important virus?" Future Microbiology, vol. 6, no. 2, pp. 153159, 2011.

[82] National Health Service, SARS (Severe Acute Respiratory Syndrome), National Health Service, London, UK, 2019, https://www.nhs.uk/conditions/sars/.

[83] Prevention CfDCa, Middle East Respiratory Syndrome (MERS), https://www.cdc.gov/coronavirus/mers/about/ symptoms.html, 2019.
[84] J.-H. Ko, G. E. Park, J. Y. Lee et al., "Predictive factors for pneumonia development and progression to respiratory failure in MERS-CoV infected patients," Journal of Infection, vol. 73, no. 5, pp. 468-475, 2016.

[85] World Health Organization, Case Definitions for Surveillance of Severe Acute Respiratory Syndrome (SARS), World Health Organization, Geneva, Switzerland, 2003, https://www.who. int/csr/sars/casedefinition/en/.

[86] S. Khan, "Emergence of a novel coronavirus, severe acute respiratory syndrome coronavirus 2: biology and therapeutic options," Journal of Clinical Microbiology, vol. 58, no. 8, 2020.

[87] M. C. Keightley, P. Sillekens, W. Schippers, C. Rinaldo, and K. S. George, "Real-time NASBA detection of SARS-associated coronavirus and comparison with real-time reverse transcription-PCR," Journal of Medical Virology, vol. 77, no. 4, pp. 602-608, 2005.

[88] L.-l. Xu, Z.-h. Hu, H.-l. Wang, X. Han, and F. Deng, "Evaluation of sensitivities and specificities of SARS-CoV detection by real-time quantitative reverse transcription-PCR assays," Virologica Sinica, vol. 24, no. 3, pp. 187-193, 2009.

[89] J. Kim, Y. L. Yang, Y. Jeong, and Y.-S. Jang, "Middle East respiratory syndrome-coronavirus infection into established hDPP4-transgenic mice accelerates lung damage via activation of the pro-inflammatory response and pulmonary fibrosis," Journal of Microbiology and Biotechnology, vol. 30, no. 3, pp. 427-438, 2020.

[90] K. Y. C. Chow, C. C. Hon, R. K. H. Hui et al., "Molecular advances in severe acute respiratory syndrome-associated coronavirus (SARS-CoV)," Genomics, Proteomics \& Bioinformatics, vol. 1, no. 4, pp. 247-262, 2003.

[91] K. M. Das, E. Y. Lee, S. E. A. Jawder et al., “Acute middle east respiratory syndrome coronavirus: temporal lung changes observed on the chest radiographs of 55 patients," American Journal of Roentgenology, vol. 205, no. 3, pp. W267-S274, 2015.

[92] Y. Shi, Y. Yi, P. Li et al., "Diagnosis of severe acute respiratory syndrome (SARS) by detection of SARS coronavirus nucleocapsid antibodies in an antigen-capturing enzyme-linked immunosorbent assay," Journal of Clinical Microbiology, vol. 41, no. 12, pp. 5781-5782, 2003.

[93] L. L. M. Poon, K. H. Chan, O. K. Wong et al., "Detection of SARS coronavirus in patients with severe acute respiratory syndrome by conventional and real-time quantitative reverse transcription-PCR assays," Clinical Chemistry, vol. 50, no. 1, pp. 67-72, 2004.

[94] A. Bermingham, P. Heinen, M. Iturriza-Gómara, J. Gray, H. Appleton, and M. C. Zambon, "Laboratory diagnosis of SARS," Philosophical Transactions of the Royal Society of London. Series B: Biological Sciences, vol. 359, no. 1447, pp. 1083-1089, 2004.

[95] R. C. Bhoyar, A. Jain, P. Sehgal et al., "High throughput detection and genetic epidemiology of SARS-CoV-2 using COVIDSeq next-generation sequencing," PLoS One, vol. 16, no. 2, Article ID e0247115, 2021.

[96] Z. Fattahi, M. Mohseni, K. Jalalvand et al., "SARS-CoV-2 outbreak in Iran: the dynamics of the epidemic and evidence on two independent introductions," Transboundary and Emerging Diseases, pp. 1-12, 2021.

[97] H. Feng, Y. Liu, M. Lv, and J. Zhong, "A case report of COVID-19 with false negative RT-PCR test: necessity of chest CT," Japanese Journal of Radiology, vol. 38, no. 5, pp. 409-410, 2020. 
[98] L. Bouadma, F.-X. Lescure, J.-C. Lucet, Y. Yazdanpanah, and J.-F. Timsit, "Severe SARS-CoV-2 infections: practical considerations and management strategy for intensivists," Intensive Care Medicine, vol. 46, no. 4, pp. 579-582, 2020.

[99] L. T. Lau, Y.-W. W. Fung, F. P.-F. Wong et al., "A real-time PCR for SARS-coronavirus incorporating target gene preamplification," Biochemical and Biophysical Research Communications, vol. 312, no. 4, pp. 1290-1296, 2003.

[100] X. Lu, B. Whitaker, S. K. K. Sakthivel et al., "Real-time reverse transcription-PCR assay panel for middle east respiratory syndrome coronavirus," Journal of Clinical Microbiology, vol. 52, no. 1, pp. 67-75, 2014.

[101] R. Konrad, "Rapid establishment of laboratory diagnostics for the novel coronavirus SARS-CoV-2 in Bavaria, Germany," Eurosurveillance, vol. 25, 2020.

[102] Centers for Disease Control and Prevention, CDC 2019Novel Coronavirus (2019- $n$ CoV) Real-Time RT-PCR Diagnostic Panel 2020, https://www.fda.gov/media/134922/ download.

[103] I. L. Lo, C. F. Lio, H. H. Cheong et al., "Evaluation of SARSCoV-2 RNA shedding in clinical specimens and clinical characteristics of 10 patients with COVID-19 in Macau," International Journal of Biological Sciences, vol. 16, no. 10, pp. 1698-1707, 2020.

[104] D. Chen, W. Xu, Z. Lei et al., "Recurrence of positive SARSCoV-2 RNA in COVID-19: a case report," International Journal of Infectious Diseases, vol. 93, pp. 297-299, 2020.

[105] X. Li, "Molecular immune pathogenesis and diagnosis of COVID-19," Journal of Pharmaceutical Analysis, vol. 10, no. 2, pp. 102-108, 2020.

[106] D. Adachi, G. Johnson, R. Draker et al., "Comprehensive detection and identification of human coronaviruses, including the SARS-associated coronavirus, with a single RTPCR assay," Journal of Virological Methods, vol. 122, no. 1, pp. 29-36, 2004.

[107] L. L. M. Poon, B. W. Y. Wong, K. H. Chan et al., “A one step quantitative RT-PCR for detection of SARS coronavirus with an internal control for PCR inhibitors," Journal of Clinical Virology, vol. 30, no. 3, pp. 214-217, 2004.

[108] D.-f. Lv, Q.-m. Ying, Y.-s. Weng et al., "Dynamic change process of target genes by RT-PCR testing of SARS-Cov-2 during the course of a coronavirus disease 2019 patient," Clinica Chimica Acta, vol. 506, pp. 172-175, 2020.

[109] V. M. Corman, O Landt, M Kaiser et al., "Detection of 2019 novel coronavirus (2019-nCoV) by real-time RT-PCR," Euro Surveillance: bulletin Europeen sur les maladies transmissibles = European communicable disease bulletin, vol. 25, 2020.

[110] T. Ishige, S. Murata, T. Taniguchi et al., "Highly sensitive detection of SARS-CoV-2 RNA by multiplex rRT-PCR for molecular diagnosis of COVID-19 by clinical laboratories," Clinica Chimica Acta, vol. 507, pp. 139-142, 2020.

[111] I. L. Lo, C. F. Lio, H. H. Cheong et al., "Evaluation of SARSCoV-2 RNA shedding in clinical specimens and clinical characteristics of 10 patients with COVID-19 in Macau," International Journal of Biological Sciences, vol. 16, pp. 1698-1707, 2020.

[112] A. Tang, Z.-d. Tong, H.-l. Wang et al., "Detection of novel coronavirus by RT-PCR in stool specimen from asymptomatic child, China," Emerging Infectious Diseases, vol. 26, no. 6, pp. 1337-1339, 2020.

[113] K. Liu, Y.-Y. Fang, Y. Deng et al., "Clinical characteristics of novel coronavirus cases in tertiary hospitals in Hubei province," Chinese Medical Journal, vol. 133, no. 9, pp. 1025-1031, 2020.

[114] P. Colson, "Chloroquine and hydroxychloroquine as available weapons to fight COVID-19," International Journal of Antimicrobial Agents, vol. 55, no. 4, Article ID 105932, 2020.

[115] Z. Chen, Z. Zhang, S. Jiang et al., "Efficacy of hydroxychloroquine in patients with COVID-19: results of a randomized clinical trial," MedRxiv, 2020.

[116] P. Gautret, "Hydroxychloroquine and azithromycin as a treatment of COVID-19: results of an open-label non-randomized clinical trial," International Journal of Antimicrobial Agents, vol. 56, no. 1, Article ID 105949, 2020.

[117] M. Wang, R. Cao, L. Zhang et al., "Remdesivir and chloroquine effectively inhibit the recently emerged novel coronavirus (2019-nCoV) in vitro," Cell Research, vol. 30, no. 3, pp. 269-271, 2020.

[118] J. Grein, N. Ohmagari, D. Shin et al., "Compassionate use of remdesivir for patients with severe Covid-19," New England Journal of Medicine, vol. 382, no. 24, pp. 2327-2336, 2020.

[119] https://www.niaid.nih.gov/news-events/nih-clinical-trialshows-remdesivir-accelerates-recovery-advanced-covid-19.

[120] P. Luo, Y. Liu, L. Qiu, X. Liu, D. Liu, and J. Li, "Tocilizumab treatment in COVID-19: a single center experience," Journal of Medical Virology, vol. 92, no. 7, pp. 814-818, 2020.

[121] B. Korber, "Spike mutation pipeline reveals the emergence of a more transmissible form of SARS-CoV-2," 2020, https:// www.biorxiv.org/content/10.1101/2020.04.29.069054v1.

[122] S. Laha, "Characterizations of SARS-CoV-2 mutational profile, spike protein stability and viral transmission," Infection, Genetics and Evolution, vol. 85, Article ID 104445, 2020.

[123] M. Laamarti, "Large scale genomic analysis of 3067 SARSCoV-2 genomes reveals a clonal geodistribution and a rich genetic variations of hotspots mutations," PLoS One, vol. 15, no. 11, p. e0240345, 2020.

[124] L. Zhang, "Genome-wide variations of SARS-CoV-2 infer evolution relationship and transmission route," medRxiv, 2020.

[125] M. Zandi, S. Saber, S. Sanami, and A. Rasooli, "Spike protein mutations and the effects on SARS-CoV-2 pathogenesis," Journal of Cellular \& Molecular Anesthesia, vol. 6, no. 2, pp. 148-153, 2021.

[126] S. Soltani, A. Zakeri, M. Zandi et al., "The role of bacterial and fungal human respiratory microbiota in COVID-19 patients," BioMed Research International, vol. 2021, Article ID 6670798, 13 pages, 2021.

[127] J. Shang, G. Ye, K. Shi et al., "Structural basis of receptor recognition by SARS-CoV-2," Nature, vol. 581, no. 7807, pp. 221-224, 2020.

[128] I. J. Junior, "The global population of SARS-CoV-2 is composed of six major subtypes," Scientific reports, vol. 10, no. 1, pp. 1-9, 2020.

[129] L. Zhang, "The D614G mutation in the SARS-CoV-2 spike protein reduces $\mathrm{S} 1$ shedding and increases infectivity," bioRxiv, 2020. 